\title{
'Beneath This Mask There is More Than Flesh, Beneath This Mask There is an Idea': Anonymous as the (Super)heroes of the Internet?
}

\author{
Sofia Alexopoulou ${ }^{1}\left[\right.$ Antonia Pavli $^{1}$ (])
}

Published online: 6 March 2019

(c) The Author(s) 2019

\begin{abstract}
Who is Anonymous? What is the group's connection with hacktivism? Can we speak of an Internet group consisting of new 'e-Robin Hoods'? Do modern heroes still exist as a source of inspiration? The answers to these questions are not unproblematic. Many would say that the group Anonymous falls into the contemporary hero category. If so, its members, Anons, could be deemed 'reincarnations' of the mythical Robin Hood but in digital form, since they tackle corruption, repression, and injustice, as he did. Others will disagree with this view. The only safe statement is that Anonymous constitutes a global, Internet-based social movement of mostly young and dissatisfied people who have decided to follow their own strategy to oppose established global governance and order. This paper sheds light on the latest hacking activity of Anonymous against several governmental websites in Greece. According to Anonymous, it sought to protect/defend Greek citizens suffering because of the financial crisis and to teach a 'strong lesson' to the elected politicians in office. Drawing on material from videos (uploaded on YouTube), online articles from Greek newspapers, and a few online articles from international media outlets, we attempt to understand whether Anonymous follows the long tradition of Robin Hood by acting as a heroic figure/icon. This paper contributes to the semiotics of hacktivism, but also to the further investigation of the identity of Anonymous as comprising 'new Robin-Hoods' based on its staged identity and actions.
\end{abstract}

Keywords Anonymous · Hackers $\cdot$ Hacktivism $\cdot$ Robin Hood $\cdot$ Internet

Sofia Alexopoulou

sofia.alexopoulou@oru.se

Antonia Pavli

antonia.pavli@gmail.com

1 University of Örebro, Örebro, Sweden 


\section{Introduction}

Since 2009, Greece has been mired in economic and social uncertainty. People in the middle and lower socioeconomic classes have had to make substantial economic sacrifices for the country to remain in the Eurozone. Exit from this financial 'club' was perceived by the political elites and much of the public as economically harmful for the country's future. As Featherstone put it:

It is thus one of history's ironies that Greece - which invented the very name 'Europe' and so much of its identity - should be faced with some of the strongest challenges in remaining a core part of it. [15, p. 238]

During the crisis, the Greek government had to sign three memoranda intended to rescue the country from default with the assistance of a number of bailout loans in 2010, 2012, and 2015. In June 2015, capital controls were introduced in Greece and economic suffocation became a stable point of reference for citizens and private companies.

Greece's economic crisis mobilized the 'reflexes' not only of Greek citizens (i.e., through street actions) but also of the international group Anonymous. Since 2012, when its actions in the Greek milieu began, Anonymous made its presence known by hacking several websites of the Greek government, which was then passing strict austerity laws/measures. Anonymous wanted to 'wake up' the public and express sympathy for the Greek people. As a result, these hacking initiatives, as well as the actions of the Anonymous collective defending citizens' rights, have been likened to the actions of the mythical figure of Robin Hood, resulting the group being dubbed as 'e-Robin Hood' since its field of action is cyberspace $[22,43,61]$.

Why do we still recall the legend of Robin Hood, and what makes it so attractive to us? According to von Platz, the legend of Robin Hood 'illustrates a principled approach to a neglected concern of justice: what we should do about the distributive results of systemic injustices' [51]. 'Systemic injustices' refer to injustices produced by the official institutions of a given society. Such injustices can be addressed in different ways ranging from a kind of redistributive justice, as in the story of Robin Hood (i.e., take from the rich and give to the poor) to total anarchy (i.e., take law into one's own hands).

This paper constitutes an empirically-grounded study of Anonymous in the Greek setting. The aim of the paper is to investigate the similarities (or differences) between the hacktivist collective Anonymous and the legend of Robin Hood, applying social semiotics and the self-presentation theory of Goffman to videos and written texts. With reference to our empirical material, we consider the Anonymous cyberattacks against the websites of the Greek Ministry of Justice (two attacks) and Ministry of Finance, as well as the Greek government website for auctions, to be of high symbolic value. In our interpretation, the above websites were not selected randomly; instead, Anonymous intended to expose the Greek political elites by revealing its ideological message and consequently a side of its publically shared identity as a group. 
We hypothesize that both the videos and texts of Anonymous "mirror" the group's hacktivist psyche and provide essential information about the group, which helps us not only to understand and explain its behavior, but also to know, to some extent, what to expect of it in the future. Anonymous uses its virtual body as a sign vehicle, for example, through using the Guy Fawkes ${ }^{1}$ mask, to capture the attention of the viewer. While uploading videos on the Internet, Anonymous establishes an interactive relationship with the public or creates a 'cyber-performance'.

Consequently, the public creates various names or labels to describe the actions of Anonymous. These labels are either negative, such as 'e-bandits', 'cyber lynchmobs', 'cyber terrorists', and 'online avengers', or positive, such as 'freedom fighters', 'digital Robin Hoods', and 'white knights'. The uniqueness of this paper is that we are looking not only at the cyber-performances of Anonymous via its videos or texts, but also at the assumed actions of members of the group.

From this perspective and given our personal admiration of the figure of Robin Hood, we chose to explore whether or not the widely used 'e-Robin Hood' label constitutes an indispensable part of Anonymous' virtual identity by looking at its virtual body, gestures, signs, expressed discourse, and actions-in other words, the virtual and real-life cyber-performance that is part of the group's identity. As proposed by King et al. [35, p. 295], 'identity creates a set of expectations about appropriate behavior for a particular organization'. Based on these expectations of identity, we explore the behavior of Anonymous as a hacking group and consider its similarities to and differences from the figure of Robin Hood, having as our departure point the Greek setting.

This paper contributes to the semiotics of hacktivism, and to the further investigation of the Anonymous identity as a 'new Robin Hood' based on its staged identity and actions in Greece. The task of discovering the real nature of Anonymous is very demanding. For instance, Hai-Jew has noted that Anonymous is a group characterized by limited information that "comes from statements by the organization (selfdefinition), the publicized actions of the group, and the insights of others that have varying relationships to the group' [22, p. 55]. Up to the present, Anonymous continues to be a very secretive group that organizes and operates in the shadows and strictly controls the information that it releases, while the original mobilizers of each of its attacks are unknown. All these characteristics make the group a provocative

\footnotetext{
${ }^{1}$ Guy (Guido) Fawkes (born 1570, York, England-died 31 January 1606, London) was a member of a group of provincial English Catholics who planned the failed Gunpowder Plot of 1605. This plot aimed to blow up the House of Lords, killing King James and many members of parliament. Fawkes was only one-not the leader-of the 13 conspirators, but he remains the individual most associated with the failed plot because his role was to sneak into the cellar beneath the House of Lords and setting off the explosives. As a tradition, once a year, the Houses of Parliament are still searched to confirm that there are no conspirators with explosives beneath the building. The mask of Guy Fawkes came to feature in the comic series $V$ for Vendetta, representing a symbol of resistance to the fictional, fascist state of the United Kingdom. After this, the mask became a well-known symbol of the online hacktivist group Anonymous, used in Project Chanology, the Occupy movement, and other anti-government and anti-establishment protests around the world. For more information about the story of Guy Fawkes, see Macphail and Lockhart [41] and Taylor and Harris [58].
} 
case to examine, and 'breaking its code' - to embrace a term from hacking cultureshould prove instructive.

\section{Literature Overview: The Emergence of Anonymous}

\subsection{From Hacking to Hacktivism}

Anyone attempting to trace the history of hacking will note that hacking has existed since the advent of computers [30]. Following Jordan, hacking is an activity in which a specific technology is used in a way diverging from the initial purpose for which it was designed [30, p. 120]. A related new term is that of 'life hack', referring to any trick or innovative way to use technology to improve one's efficiency. Nowadays, however, the first association that someone usually makes when hearing or reading the word 'hacking' is negative. 'Hacking' evokes negative connotations ${ }^{2}$ and actions, such as illegal behavior, legal infractions, criminality, and digital disobedience. In other words, 'hacking has become associated in the mass media with illicit computer intrusion' [30, p. 120]. Like hacking, the term 'hacker' is associated with illegality. From technology geeks developing new and/or advancing existing digital technologies [32] to those using illegal actions to 'hack' existing digital technologies or infrastructures, hackers are labeled 'criminals' and 'burglars' [7].

'Hacktivism' is a term combining two actions: hacking and activism [28], or, according to Taylor, political activism [57]. The purpose of hacktivism is 'to combine hacking tactics within the context of [a] political agenda' [58], while Karagianopoulos has claimed that hacktivism is 'any use of digital technologies for political reasons' [32, p. 6]. While hackers' field of action is the technical, hacktivists' field of action lies between the technical and the social [57]. Hacktivists' actions are not intended to damage the selected targets-i.e., people or property-or to benefit the hacker-activist [42, p. 15]. Instead, motivated by their political views, they adopt hacking tactics as another means to perform activism, a form of activism that does not occur in the real world, but in the virtual world, in cyberspace. Imitating non-violent forms of civil disobedience in the real world, for example, sit-ins on the streets [31], denial-of-service (DoS) attacks and distributed denial-of-service (DDoS) attacks [4] could be considered forms of electronic civil disobedience employed by hacktivists to protest in cyberspace. ${ }^{3}$ Like the activists or protesters

\footnotetext{
2 'Life hack' as a term has positive connotations, since it applies to any trick, shortcut, skill, or novelty that makes life easier. The term was coined in 2003 by tech writer Danny O'Brien, who used it to describe how programmers were able to develop shortcuts to make their daily lives more efficient, and since then the term has 'gone viral'.

3 The difference between DoS and DDoS attacks is that the latter are more advanced in that it is not just one Internet user attacking one website. Instead, multiple Internet users simultaneously attack a specific website to create high traffic and, consequently, to make the latter inoperable/unavailable. The DDoS attack does not attempt, for example, to alter or harm the content of the attacked website, but, like protest in the streets, the purpose of this attack is 'to remove the target from the Internet, denying it service by overwhelming it with masses of requests for information' [30, p. 124].
} 
participating in non-violent sit-ins [30], the Internet users or hackers who conduct DoS or DDoS attacks do so to disrupt access to specific websites for specific purposes [54].

The hacker-activists or 'freedom fighters' [31] who constitute the hacking community do not all share the same goals. Some prefer to break codes and search for the vulnerabilities of digital infrastructures while remaining in the shadows and shunning publicity [9]. Others, while they also want to break codes and expose the vulnerabilities of digital infrastructures, also want to attract as much publicity as possible [8]. A hacktivist collective that falls into this second category is the Anonymous movement and, according to Gabriella Coleman, 'Anonymous seeks publicity before and after every successful action' [8, p. 3]. The Anonymous movement has one more attribute that distinguishes it from other hacking movements: Anonymous members are not just activists with high skills in hacking; instead, anyone who wants to join the movement can do so, even though s/he lacks hacking-related skills [9].

\subsection{From the Anonymous 4chan Users to the Anonymous Hacktivist Collective}

Anonymous made its first public announcement on 29 July 2007 by uploading a video on YouTube [10]. With this video, Anonymous tried to answer the Fox News criticism describing the collective as a group of 'ultimate purveyors of Internet pranking and trolling' ${ }^{4}[9$, p. 2]. This video marking the 'birth' of Anonymous shows a suited, headless man and provides some basic information about the group's actions, saying:

The name and nature of Anonymous has been ravaged ... We are everyone and we are no one ... We are the face of chaos and harbingers of judgment ... We mock those in pain. We ruin the lives of others simply because we can ... We are the embodiment of humanity with no remorse, no caring, no love, and no sense of morality. [9, pp. 1-2]

In its initial public appearance, Anonymous displayed the characteristics of a group of 'emotionless avengers' without deep political reflection.

Before that, the roots of the Anonymous movement go back to the mid 2000s, specifically, in 2003 when the 4chan website was launched by Christopher Poole. The idea behind 4chan is that any user can upload pictures or messages either under his/her own name or anonymously [36, see also 8]. As for the topics shared and found on 4chan, there is no limitation, since any user can post about anything. However, as Coleman stated, '[an] important thing about 4chan is to have a thread that really explodes and lasts for a long time; if it doesn't then it disappears' [36, mm. 14:43-14:55]. Up to that time, the 'Anonymous' movement was a group of Internet users and/or activists who criticized the news media through trolling. For example,

\footnotetext{
4 Trolling is a slang term used on the web to describe an activity in which some Internet users try to upset other Internet users. By posting aggressive or irritating messages in online forums or social media, Internet users aim to provoke and/or make fun of other users and to start online arguments.
} 
Fuchs described the Anons' actions 'as fun of the users', without paying attention to other institutions, such as big companies and governments [17].

Early in 2008, however, one post on/b/board-one of the most popular 4chan boards-by an anonymous 4chan user prompted the rest of the 4chan community 'to do something big' against the Church of Scientology. The point of departure for this mobilization/campaign was the leak of a video from the Church of Scientology in which Tom Cruise-a well-known actor who had admitted being a member of Scientology-expressed his enthusiasm and devotion to Scientology doctrines [45]. Although this video ended up being mocked by many Internet users, it was the reaction of the Church of Scientology, and its attempt to delete the video as soon as possible, that offered a fertile basis for anonymous 4chan users to attack it [45]. According to Norton, the answer to the questions 'Was Anonymous serious about destroying the Church? Was it all a joke?' is 'yes' [45]. The attack on the Church of Scientology ended up being crucial in transforming the Anonymous movement from a rather indifferent hacking/trolling group into a movement claiming a political voice [8], indicating that 'lulz' ${ }^{5}$ actions 'have a real world-effect' [45].

The political action of Anonymous expanded in 2013 through its campaign to oppose the attack on the WikiLeaks website. Specifically, in November 2013 a large number of classified documents belonging to the US government was published on the WikiLeaks website [24]. A few days after the release of these documents, the WikiLeaks website experienced a DoS attack and, consequently, was rendered inactive. A few days later, the WikiLeaks website was again online, being hosted by Amazon.com [24]. The Amazon.com decision to offer hosting services to WikiLeaks and the release by WikiLeaks of US government classified documents provoked reactions in the US political context. Senator Lieberman became involved in this debate by asking Amazon.com to explain its decision to host the WikiLeaks website [24]. The outcome of this political debate was that Amazon.com stopped offering hosting services to WikiLeaks. This decision influenced some other popular websites, such as those of MasterCard, PayPal, and Visa, which also provided services to WikiLeaks, to terminate their collaboration with WikiLeaks [24].

The Amazon.com decision to discontinue hosting the WikiLeaks website and the MasterCard, PayPal, and Visa decisions to stop providing payment services to WikiLeaks prompted Anonymous to become involved in this controversy [47]. By employing a DDoS tactic, Anonymous attacked these online payment services. As a result, their websites either crashed or became unavailable for some time. According to Hampson, Anonymous' involvement in the WikiLeaks controversy was interpreted as a campaign intended 'to raise awareness of the actions' of WikiLeaks opponents, 'to fight what it perceived to be censorship by identifying and attacking those responsible for the attacks on WikiLeaks' [24, p. 513]. It should be noted here that DDoS tactics are forms of electronic civil disobedience

\footnotetext{
5 The term 'lulz' is an acronym deriving from the phrase 'laugh out loud' and is a corruption of L.O.L. Within the context of Anonymous actions, 'lulz' is not only used to describe the physical reaction of laughing. Instead, 'lulz' embeds a deeper meaning combining both the action of laughing and the action of revenge in order to highlight a given injustice in society.
} 
preferred by Anonymous. As Coleman explained regarding the actions of Anonymous, their initial purpose is not to harm the digital infrastructure that they are attacking, but, by using hacking techniques, to highlight vulnerabilities in the digital infrastructure of large corporations and governmental websites [8]. In other words, DDoS attacks function as a 'political weapon' [8] in the hands of Anonymous hacktivists, by illustrating their 'power' against the state's infrastructure and corporations.

As mentioned earlier, the emergence of Anonymous as a hacktivist movement occurred after its members interacted on the 4chan boards. Gradually, their simple and fun-seeking interactions became transformed into a 'movement' or 'collective' with political or sociopolitical motives. Anonymous became active in various projects and political struggles; its members-labeled 'Anonymous Robin Hoods'-significantly changed their former rhetoric, which had categorized them simply as emotionless avengers or people who wanted to have fun. In recent years, Anonymous has clearly taken some forms of political action, such as hacking several Tunisian governmental websites during the 2011 protests [11] and spreading some of the first calls to occupy Wall Street [33].

According to its motto, anyone can join Anonymous: there are no limitations or specific criteria for joining the movement [32]. Therefore the 'Anonymous Robin Hoods' chose as their 'personal sign' the mask of Guy Fawkes, as well as the headless man. As Olson put it, 'there is no structure or leadership ... they were not a group but everything and nothing' [47, p. 7]; as well, Anonymous has no manifesto describing the scope of its hacktivism [45]. While the group lacks a specific manifesto, a main argument of Anonymous members, and their priority as well, is that information should be free and everyone should have access to it [45]. On this matter, Coleman has stated that the Anonymous collective shares:

a foundational commitment to the maintenance of anonymity and a broad dedication to the free flow of information, Anonymous has no consistent philosophy or political program. While increasingly recognized for its digital dissent and direct action, Anonymous has never displayed a predictable trajectory. [9, p. 3].

Considering the 'unique' constitution of this movement, having no specific requirements for membership as well as no leadership, and the variety of its actions, which occur in both cyberspace and real space, encompassing everything from cyber protests and cyberattacks to street protests, one question concerns the form of this hacktivist collective or movement. Christian Fuchs defines Anonymous as

social movement and anti-movement; it is collective political action based on a shared identification with some basic values (such [as] civil liberties and freedom of the Internet) that results in protest practices online and offline against adversaries, and at the same time for many of those engaging on Anonymous platforms individual play and entertainment. [17, p. 347]

Another view of the Anonymous collective is that of Shalin Hai-Jew, who, though she approaches Anonymous as a sociopolitical movement, also stresses 
that the lack of a specific ideology is an issue that leaves room for questions regarding the group's structure [22]. She claims that the existence of a specific defining ideology is crucial for any social movement's recruitment of new members [22]. In the case of Anonymous, however, no specific ideology defines the purpose of the group.

\section{3 'Improper Names': The Case of Anonymous}

The Internet is itself a network, and also has the ability to create networks of scattered individuals. The Internet and easy access to it has allowed individuals to upload videos, create blogs, and exchange ideas on forums, giving impetus to the distribution of messages across national borders. Through this wave of technological progress, Anonymous managed to promote its actions as no one had before, at the press of one button.

In this section, we argue that the name 'Anonymous', along with the group's various nicknames (e.g., 'e-Robin Hood'), conveys something of Anonymous' identity or, more accurately, virtual identity, since how we name something confers certain qualities on the thing named. Moreover, we argue that the group's identity can be discerned not only from the cyber-performances that Anonymous offers to the public but also from its assumed actions.

As commented earlier, there is some consensus among scholars studying the actions of this unique politically motivated collective that Anonymous is a shadow entity, which is why it deploys an obscure name for its purposes. According to Deseriis [12, p. 41], Anonymous is 'an improper name' because it does not 'designate a clearly defined domain'. Deseriis classifies Anonymous as an improper name for three key reasons. First, the name Anonymous is constructed to obscure the identity of a collective, while also allowing the mutual recognition of its users [12, p. 41]. Second, this improper name transfers symbolic power to those who do not have a voice in the typical institutional setting and, finally, this improper name entails a certain level of publicity and dissemination while making it very difficult to predict the name's future usage [12, p. 41]. This means that the Anonymous of today may differ from the Anonymous of the future-in other words, the organization can adjust or transform itself to respond to new circumstances by keeping its name intact.

Anonymous belongs to a wide-ranging virtual movement, many of whose members have a regional focus [12, p. 42]. In this sense, it is logical to assume that some of the members may also have a personal interest in participating in the conducted attacks. Despite the organizational fluidity of Anonymous, the use of 'the same pseudonym, iconography, and set of rhetorical strategies within different national contexts has had the effect of linking an emerging global "hacker class" [12, p. 42]. This hacker class uses symbols recognizable by all of its members, symbols that serve as a way of self-presentation in the cyber arena, similar to that of a unique and identifiable online signature.

The issue of self-presentation was studied by Goffman in his seminal work "The Presentation of Self in Everyday Life" [19]. Goffman conceptualized that 
people introduce their 'self' on a daily basis through a constant process of information management ('performance'). Individuals tend to present an idealized self, instead of their real one. This performance has two parts, the 'front region' (front-stage) and the 'back region' (back-stage). Within Goffman's dramaturgical approach, the social actor uses expressions 'given' and 'given off'. 'Given' expressions materialize signs, usually in a verbal form, while 'given off' expressions materialize signs, usually in an unintentional, nonverbal form, such as body language.

Echoing the ideas of Goffman, Robinson [53] developed the term 'cyberperformers' to describe individuals who perform on the Internet:

In this way, vocabulary, content and phrasing of the postings become identity performance; the goal of a performance is to reaffirm a community's shared moral values [19]. Online performance takes place through the language used in messages and postings that are rich sources of expressions 'given' and 'given off'. For the performance to be successful, the cyberperformer must become literate in terms of site or community language, as well as implicit and explicit shared values... For users to successfully maintain their membership in a community, they must perform self-identities that do not violate the context of community interaction'. [53, p. 106]

Through this lens, Anonymous can be viewed as comprising cyber-performers who present recorded, online spectacles to a certain audience and interact with the viewers of its videos by playing the role of a 'counter-system authority', though without offering much information about its backstage identity, which is the real one. This means that we get information only about the front-stage identity. Specifically, World United Anonymous has described Anonymous as:

Anonymous in general is an idea, as said before, everyone is entitled to an idea. If you choose to use the name, you can help by spreading knowledge, making videos, music, tweeting, just being a good person, etc. ... The name 'Anonymous' just helps put all our ideas in one place so people find them easily. Anonymous is not a group, nor is it an army, person, or even a movement. Anonymous is simply a main idea which is home to a collective of ideas. [16, p. 101]

Fish attempted to compile the symbolic culture of Anonymous, which in his view validates the 'improper name' attributed to the group of Anonymous and consequently its versatile virtual identity [16, p. 101]. This symbolic culture includes: the smiling black-on-white Guy Fawkes mask that, after the release of the movie $V$ for Vendetta in 2005, became emblematic of broader protest [16, p. 101]. Several videos present masked newscasters, while others have the quality of hostage videos. The written language is always serious and frightening, with the spokesperson using either first-person (us) or second-person (you) modes of address.

Other distinguishing elements of the group are the introductory logo, the textto-speech (TTS) narration, intense classical or techno music, and the traditional 
concluding remarks 'we don't forgive, we don't forget, expect us' [16, p. 101]. The logo, icon, and TTS tonality are transferable assets, and anyone can download and edit the spinning globe introduction, a waving character in a Guy Fawkes mask, a TTS voiceover, and an apocalyptic text [16, p. 101].

That being said, the question that arises next is whether calling Anonymous 'e-Robin Hood' makes sense given the group's virtual identity, or whether it is just another 'improper name'. Before answering this question based on our empirical material, we will discuss how we interpret the relationship between Anonymous and the figure of Robin Hood.

\subsection{Robin Hood and Anonymous: Is There a Connection?}

We have all come across the stories of Robin Hood. This marvelous character-if he existed at all-has been popularized through various books, TV series, movies, documentaries, and video games. Who was he and what makes him so attractive, even today? Robin Hood was a late-medieval hero in England [50, p. 3], and the stories of his deeds vary among the surviving sources, with early stories about him being composed in rhyme and disseminated via ballads, to be recited for contemporary audiences who were unable to read.

The surviving stories highlight different qualities of Robin Hood, which leads us to speak not of a single Robin Hood, but of several versions of him. For example, some stories depict Robin Hood as descending from a yeoman family (i.e., proto middle class), while others claim he had more humble origins. Therefore, it is almost impossible to determine whether or not Robin Hood really existed.

The kernel of almost every version of the myth is that Robin Hood and his companions fought the cruel governance of Prince John and his associate, the Sheriff of Nottingham. His life's mission was to take from the corrupt rich and give to the poor, meaning that he cared for the weak in a tangible way and did not seek personal gain, as typical bandits do. This made him a sort of 'social robber' [27], despite the obvious antithesis between the terms 'social' and 'robber', or in modern terms a 'hero'. Robin Hood's weapons were the longbow and sword.

According to Hobsbawm [27, p. 504], it is very difficult for someone to find a 'pure Robin Hood' for two reasons:

(a) because to avoid or reject the temptations of power and wealth requires a degree of political consciousness which is rarely to be found among such men [i.e., bandits], and (b) because to do so implies the rejection of most of that support and protection from the local power-structure, which is so helpful to the bandit who wishes to pursue a successful career.

Hobsbawm [27, p. 504] made another attention-grabbing observation by emphasizing that public opinion has the final call in determining who are the 'good' bandits, the 'bad' bandits, and the 'indifferent' ones, as in the case of Robin Hood. With this in mind, the public seems to be able to clearly distinguish the outlaws who make a difference in their community, even if in the end, the 
Table 1 A comparison between Robin Hood and Anonymous

\begin{tabular}{|c|c|}
\hline Characteristics of Robin Hood ("a social robber") & Characteristics of Anons as Robin Hood figures \\
\hline Protagonists & Protagonists \\
\hline $\begin{array}{l}\text { Robin Hood and his merry men-the merry men } \\
\text { are not all known }\end{array}$ & $\begin{array}{l}\text { Unknown - any citizens could be Anonymous } \\
\text { members }\end{array}$ \\
\hline Place of activity ('war') & Place of activity ('war') \\
\hline Sherwood Forest & Cyberspace or the CyberHood \\
\hline Weapon & Weapon \\
\hline Longbow and sword & $\begin{array}{l}\text { Keyboard, DDoS attacks, 'doxxing', and 'leaking' } \\
\text { confidential information }\end{array}$ \\
\hline Enemy & Enemy \\
\hline Prince John and the Sheriff of Nottingham & $\begin{array}{l}\text { The enemy varies (e.g., large corporations and } \\
\text { national governments) }\end{array}$ \\
\hline Logic behind the pursued actions & Logic behind the pursued actions \\
\hline Taking from the rich to give to the poor & $\begin{array}{l}\text { Not consistent. Sometimes the group acts under the } \\
\text { logic of 'lulz' and other times pursues causes of a } \\
\text { more political nature }\end{array}$ \\
\hline
\end{tabular}

exact same public seems to confuse some of the real facts of the bandit's life with fictional ones which belong to the realm of myth.

In our epoch, many have described the members of Anonymous as new Robin Hoods $[6,22,43,61]$. Through their hacking actions, Anonymous wants to ensure that its 'enemies/the offenders' pay a price for their misdeeds while the group performs actions for a number of causes. As noted by Deseriis, [12, p. 42], Anonymous demonstrates an incredible ability to link economic and political grievances, and this ability gives a universal dimension to its messages, because every country encounters to a greater or lesser degree issues of this nature. The group's recent hacking strategy usually clothes itself in the mantle of righteousness, morality, and social justice, in comparison with its past, when the group organized apolitical pranks. To get a better idea of the Anonymous persona, Thomas has emphasized that the:

hackers perceived themselves as ethical outlaws or cyber-Robin Hoods for whom the motives of the act, not the rules proscribing the act, defined the morality of their enterprise. The mantra 'hacking is a moral imperative' provided the primary precept for the hacker ethic and their primary goal of knowledge acquisition. [60, p. 605]

Analogous to the Robin Hood myth, Anonymous has as its key weapon the 'digital arrow', i.e., DDoS, which 'shoots' from the 'keyboard'. Other classic practices of the group are 'doxxing', which is the exposure of the real identity of offenders, resulting in their public shaming [5, p. 3], and the 'leaking' of confidential information, exposing secrets and issues that might otherwise have remained underreported or hidden from the public eye [52]. At this point, it is also worth mentioning the 'chaotic and selfish side' of Anonymous, which 'attacks and harasses randomly selected corporations and people for the sole purpose of the lulz' [61, p. 65]. This dark-selfish side of the Anons ('lulz') does not easily conform to the heroic portrait 
of Robin Hood, but more to the image of avengers, and this stance was more obvious during the first online steps of the group's activity.

In Table 1 we present the observable similarities and differences between Robin Hood and the members of Anonymous.

\section{Methodology}

For the purposes of this paper, we employed social semiotics and the theory of selfpresentation as studied by Goffman. Here, we briefly introduce the theoretical basis of social semiotics and self-presentation theory. The interested reader can refer to the original papers, shown in the reference list.

Our study took into account the work of the key representatives of the field of social semiotics, i.e., [23, 26, 28, 29, 37, 38, 49, 62, 63]. Social semiotics is not a 'pure' theory but a form of enquiry that allows researchers to formulate questions about the phenomena under scrutiny. Social semiotics is the study of social sensemaking and of the power of human processes of signification-interpretation, which occur at both the individual and social levels. The key element of this theory is social resources or signs. Van Leeuwen described these resources or signs as follows:

Semiotic resources are the actions, materials and artefacts we use for communicative purposes, whether produced physiologically - for example, with our vocal apparatus, the muscles we use to make facial expressions and gestures or technologically - for example, with pen and ink, or computer hardware and software- together with the ways in which these resources can be organized. Semiotic resources have a meaning potential, based on their past uses, and a set of affordances based on their possible uses, and these will be actualized in concrete social contexts where their use is subject to some form of semiotic regime [63, p. 298].

Signs can also be ideas or thoughts, as stated by Peirce [cited by [41], p. 301]. The task of finding signs is not easy, but deserves our effort. The real danger is in searching for signs that do not, in fact, exist. We should therefore be clear that social semiotics does not create signs but attempts to bring them into the light.

People use signs to promote their public image and crystallize specific impressions of themselves. Goffman suggested that every social interaction entails a fundamental dialectic between an individual who is in physical proximity to other persons: 'The individual tends to treat the others present on the basis of the impression they give now about the past and the future. It is here that communicative acts are translated into moral ones. The impressions that the others give tend to be treated as claims and promises they have implicitly made, and claims and promises tend to have a moral character' $[40$, p. 21$]$.

The individual usually wants to control the impressions she shares with her audience, and when the viewer of the spectacle does not know the identity of the 'performer' on the social stage (see, e.g., Anonymous), the viewer must rely on representations, which could lead to misinterpretation. The obligation always to 
act in a steady moral way or to play one's everyday role with consistency encourages the performer to eventually become the person who is appearing on stage.

The individual as performer is not passive, but learns from her mistakes and adjusts/improves her own performance, dramaturgical skills, and strategies. The individual as performer must not be confused with a theatrical character, because the latter 'is not in some ways real, nor does it have the same kind of real consequences as does the thoroughly contrived character performed by a confidence man' [40, p. 25].

As noted above, the sociological approach of Goffman emphasizes face-to-face interaction, which of course is not the rule on the Internet and particularly not for Anonymous. In his essay 'Replies and responses' [21, pp. 14-15], Goffman analyzes conversation as a system with its own characteristics:

1. A two-way capability for transceiving acoustically adequate and readily interpretable messages.

2. Back-channel feedback capabilities for informing on reception while it is occurring.

3. Contact signals: means of announcing the seeking of a channeled connection, means of ratifying that the sought-for channel is now open, means of closing off a theretofore open channel. Included here, identification-authentication signs.

4. Turnover signals: means to indicate ending of a message and the taking over of the sending role by next speaker. (In the case of talk with more than two persons, next speaker selection signals, whether 'speaker selects' or 'self-select' types.)

5. Preemption signals: means of inducing a rerun, holding off channel requests, interrupting a talker in progress.

6. Framing capabilities: cues distinguishing special readings to apply across strips of bracketed communication, recasting otherwise conventional sense, as in making ironic asides, quoting another, joking, and so forth; and hearer signals that the resulting transformation has been followed.

7. Norms obliging respondents to reply honestly with whatever they know that is relevant and no more.

8. Non-participant constraints regarding eavesdropping, competing noises, and the blocking of pathways for eye-to-eye signals.

As well as this system of talk, there is also the non-verbal communication of the body. Non-verbal communication ('body idiom') cannot always be controlled and thus can unintentionally reveal many things about the performer, in particular:

Although an individual can stop talking, he cannot stop communicating through body idiom; he must say either the right thing or the wrong thing. He cannot say nothing. Paradoxically, the way in which he can give the least amount of information about himself - although this is still appreciable - is to fit in and act as persons of his kind are expected to act [20, p. 35]. 
Anonymous communicates its actions to the public in different ways (Hai-Jew) using either the popular video-sharing space of YouTube or Facebook pages; accordingly, this study relied on material comprising videos (uploaded on YouTube) [3, 44, 64], online articles from Greek newspapers, and a few online articles from international media outlets $[1,2,13,14,18,48,55,56,59]$. We treated videos as a category of visual semiotics, similar to the examination of pictures, drawings, paintings, photographs, colors, print ads, posters, design, films, diagrams, logograms, traffic signs, and maps [46, p. 298]. Videos represent a more advanced way to achieve ideological ends, since they combine various modes of communication (e.g., graphics, text, photographs, and music).

On this basis, we tried to indicate whether or not there are any similarities between the figure of Robin Hood and Anonymous through exploring the diffused signs, rhetoric, and actions of the latter. We share the view of Hardy et al. [25, p. 62], who emphasized that 'our focus is on collective identity as a linguistically [and semiotically, we would add] produced object embodied in talk and other forms of text [but not only text, as we elaborated above], rather than as a set of beliefs produced in members' minds'. We accordingly organize the analysis of our empirical material as follows:

(1) The placement of semiotic signs/resources that constitute part of the Anonymous cyber-performances: we identify the basic semiotic repertoire found in the Anonymous videos that forms part of their average performance.

(2) Interpretive textual analysis: we seek to understand the vocabulary (e.g., grammar and metaphors) by which the message is organized and communicated to the viewer.

(3) Power relations generated from the cyber-performances: we situate the actions of Anonymous in a specific ideological camp and explore whether or not this camp is somehow associated with the archetype of Robin Hood.

The first two steps are undertaken simultaneously for each cyber-attack, while the final one is presented as a common point of reference for all examined cyber-attacks.

To find the materialized signs, we repeatedly watched and read the relevant videos and selected texts. We kept personal notes and, after watching and reading the material, we compared our notes. The final step was to merge our notes into one draft, considering: the various ways (i.e., signs) that Anonymous uses to 'push' its message to the reader by using signs in a naturalized way; the ultimate goal (i.e., hidden message) of Anonymous in ideological terms; and whether we could identify the operative power relations. Signs may have multiple meanings, and we do not claim to have arrived at the definitive interpretation. However, because as social science researchers we have close proximity to the Greek case (i.e., knowledge of the historical background and of the new social conditions created by the economic crisis), we believe that our interpretations are plausible.

The four selected cyber-attacks were undertaken in Greece by Anonymous between 2012 and 2017, targeting the Greek Ministry of Justice (two attacks), the Greek Ministry of Finance, and the governmental website for auctioning real estate in Greece. The Greek ministries of Justice and of Finance had the burdens of applying the austerity measures amid the Greek financial crisis, and of satisfying 
the wishes of the foreign creditors to ensure the country's economic survival. As a result, these cyber-attacks had high symbolic value.

It is worth mentioning that, regarding the cyber-attacks on the Greek Ministry of Justice, we downloaded the relevant videos to our archive of Anonymous videos on YouTube. For the remaining attacks, we only have the relevant texts, since the videos were unavailable on any official communication channel of Anonymous or on YouTube when this study was being conducted. Those primarily exposed to the messages of Anonymous in cyberspace are 'typical' users of the hijacked websites, as well as individuals who surf widely used platforms such as YouTube and Facebook.

\section{Analysis of the Cyber-Attacks}

\subsection{First Attack on the Greek Ministry of Justice, February 2012 (Video)}

Anonymous attacked the Ministry of Justice twice, first on 2 February and then on 22 February 2012 [2, 13]. In the first attack, a DDoS attack, Anonymous put the Ministry of Justice website out of service, informing the public of its action and its purpose through a video uploaded to YouTube. The Anonymous speaker wearing a mask and a robe criticized Greece's bailout by the European Union and the International Monetary Fund. The key message of the video was that 'justice is coming'. The exact message was:

Greetings Greece. We are Anonymous.

What is going on in your country is unacceptable. You were chosen by your people to act on behalf of them and express their wishes, but you have derogatorily failed. You have killed the most sacred element your country had and that is democracy. Democracy was given birth in your country but you have now killed it. What an irony! Your own people hate you and you stare at them doing nothing to prevent that. You have joined the IMF against your people's acquiescence. You have so introduced a new dictatorship upon your people's shoulders and allowed the bankers and the monarchs of the EU to enslave them both economically and politically. They pay their government's mistakes heavily and you made foreign people hate them for something they are not responsible for. What a shame! Police is taking advantage of its powers and attacks people who demonstrate in order for justice to be done. They demonstrate against you but you do not want their voices to be heard. You deprive them from their right of freedom of expression and of their right to live. Your arbitrary actions must be punished. By signing the ACTA bill you are going to deprive your people from further freedom and you are pushing them one step towards oppression. You ignored our warnings and now WE ARE IN CHARGE!

We are Anonymous

We are Legion

We do not forgive 
We do not forget

You should have expected us!

People should not be afraid of their governments.

It's governments that should be afraid of their people.

The placement of semiotic signs/resources constituting part of the Anonymous cyber-performance: Accompanied by strong, immersive background music, the video starts with the image of a spinning globe and a headless suited figure with a question mark where the head should be. It should be noted that in the upperleft corner of the video is a symbol recalling the United Nations logo, evoking the universality of the Anonymous movement. This peculiar logo remains visible for almost the whole duration of the video.

The protagonist of the video is someone wearing a Guy Fawkes mask-which symbolizes anonymity and rebellion against authority—and a black robe. The choice of a black robe was not accidental, as black is a sign of disobedience, power, rebellion, and piracy on the Internet. The black robe also recalls the clothing of judges, who all used to wear black robes as a symbol of unity, implying that all judges are equal. Moreover, simplicity is the main characteristic of their appearance, and no matter who the judge, she should be given respect for her role in delivering justice. As Kress and Van Leeuwen noted, color is a language in itself that can be used to:

convey 'interpersonal' meaning. Just as language allows us to realize speech acts, so colour allows us to realize 'colour acts'. It can be and is used to do things to or for each other, e.g. to impress or intimidate through 'power dressing', to warn against obstructions and other hazards by painting them orange, or even to subdue people [39, p. 348.].

As noted by Kress and Van Leeuwen, the choice of black clothing by the hacker 'anchorman' was intended to show that he, and the hacktivist collective for which he speaks, represents power and rebellion that will oppose the government via cyberspace.

In the video, the hacker is sitting and his gestures seem calm, giving the impression that he is confident in his actions. The viewer can only see the person from the waist up, and the video often zooms into the face of Anonymous - or more correctly the mask of Guy Fawkes. The Anonymous spokesman resembles someone presenting the news on a typical TV channel, and holds a white paper in his hands. He is looking directly at the viewers, demanding their full attention. The presentation recalls a breaking news event, enacting several different feelings and emotions in the audience, ranging from fear, upset, and nervousness to curiosity, surprise, and suspense about what is going to follow.

Around the middle of this video, the quality of the image starts to deteriorate. The poor quality of the video is another way to illustrate its 'underground', 'piratical' nature and the connection with hacking. Hacking actions happen 'underground', intruding on the conventional. In line with this, the sound quality of the narrator's voice also becomes distorted.

The video ends with the famous motto from $V$ for Vendetta, that 'People shouldn't be afraid of their government. Governments should be afraid of their 
people' [3]. Then, two images appear, the first depicting politicians wearing the Guy Fawkes mask, which is closely associated with the group's culture, and the second depicting a Greek protestor being beaten furiously by policemen.

Interpretive textual analysis: Regarding the selection of the target, the Ministry of Justice, we contend that this choice was not accidental; rather, it included indirect, embedded criticism leveled against the Greek government and its political choices during the first years of the economic crisis. In this video, Anonymous stresses the notion that 'justice is coming', and that this is what they are fighting for.

In this digital attack against the Ministry of Justice, Anonymous had a message about its choices and actions for Greek political elites, that is, that the digital infrastructure of the Ministry of Justice was just as vulnerable as the concept of justice in Greek society. At the end of the video, Anonymous exhibited a photo, likely of the British Parliament, with politicians wearing Guy Fawkes masks, showing that Anonymous is potentially keeping an eye on them, and will finally come into power and destroy the existing and distorted system of parliamentary democracy that represses its citizens.

Another signifying message that Anonymous promoted through this video concerns the concept of democracy, which was especially poignant at a time when Greece was governed by an interim three-party coalition cabinet not elected by the citizens. According to Anonymous, the interim cabinet that succeeded the government elected by Greek citizens can be understood as the 'killing' of democracy in Greece. The contradiction between the past glory of Greece, which, as noted by Anonymous gave birth to democracy, and the current situation is difficult to overlook.

Furthermore, Anonymous charged the unelected Greek government with beating, via the police, the demonstrators who were protesting in the name of democracy, presenting an image supporting that charge, i.e., the image of the beaten Greek protester. The latent message is that Anonymous does not forgive unfairness towards the weak and will not sit by quietly.

Throughout the video, it is easy for the viewer to notice the "catchy phraseology' and the supporting images (e.g., of the Greek demonstrator) intended to attract viewer interest and create vivid imagery and symbolic signs in their minds. This tactic is clever, since the message directly appeals to the emotions of the audience by defending the weakest citizens.

Taking the textual and visual material together, this video can be interpreted as presenting more than the performance of the hacker as an 'anchorman' announcing breaking news. Focusing on his performance, and based on how that the hacker reads this 'announcement', one sees that it includes more than just elements intended to inform the public. Instead, his performance, that is, his tone of voice, appearance (i.e., the Guy Fawkes mask and black robe), bodily posture (i.e., looking directly at the viewer), recalls a courtroom image. Through this performance, the hacker's identity as a judge is evoked. As the judge in court announces his/her verdict to the plaintiff and accused, dispensing justice, so the hacker, by performing the identity of the 'cyber-judge', is seeking social justice. The Anonymous video could be viewed as a 'cyber-court' and its message 
a verdict against the Greek government, explaining the purpose of the attack against the Ministry of Justice.

\subsubsection{Second Attack on the Greek Ministry of Justice, February 2012 (Video)}

A few weeks after its first attack, Anonymous disabled the Ministry of Justice website, uploading a new video. This attack was a response to the police arrests of three members of the Greek Hacking Scene (GHS), demonstrating their solidarity with them. In its message, Anonymous stressed that the three arrested GHS 'boys' had nothing to do with the first attack on the Ministry's website and should therefore be freed immediately. This attack did not focus solely on the above-mentioned arrest, but went on to describe in detail the difficulties the Greek people were facing due to the austerity measures: soup kitchens in schools, homelessness, people searching for food in garbage bins, and high unemployment. In this context, Anonymous considered the Greek government an 'occupying force' for dissolving the Constitution and driving the people of the country to despair.

In this video, Anonymous continued to criticize the Greek politicians' undemocratic action. As Anonymous stated, 'Democracy in Greece is dying. It died the same moment a government took office that had not been elected by the Greek people'. Furthermore, Anonymous warned the government to vote against the bill imposing a new loan 'which will be the last nail in the coffin of the Greeks', and asked Greece to exit from the IMF, refuse to pay interest to 'loan sharks', and hold immediate elections. Otherwise, if the Greek government passed unfair legislation, then Anonymous would attack the digital infrastructure of the tax offices to protect the taxpayers by deleting their debts.

The word chosen to refer to the lenders deserves mention. Although the term used since the outbreak of the economic crisis to describe the International Monetary Fund, European Commission, and European Central Bank was 'lenders', the Anonymous collective called them 'loan sharks', a negative term loaded with fear.

In another part of this video, Anonymous stressed that they were greater in number than the members of the Greek parliament: 'There are millions of us and you are only 300. In this war, teargas will not be of any use to you', adding that 'the cyberattack on the Ministry's website is only a small sample of what we can do'; 'In the Greek demonstrations, you can treat the demonstrators with unbelievable violence, hitting unrelentingly, but the Internet is our own field. And we like this war.

The message concludes with the promise that Anonymous will be on the side of the Greek people and repetition of the message that 'justice is coming'.

The placement of semiotic signs/resources constituting part of the Anonymous cyber-performance: At the top of the video there is an image of a group of young protesters sitting in Syntagma Square and the logos of Anonymous (i.e., a pyramid including the watchful eye of the Illuminati, a headless, suited man with a question mark where his head should be, and the mask of Guy Fawkes). This time the video does not present a single representative wearing the Guy Fawkes mask; instead, the visual material is shaped by a song, entitled "Take control" by Vakttus, and text in green lettering appearing against a black background. 
In this attack, while there is no physical appearance by a member of Anonymous, the group's identity is performed indirectly, in that the choice of song and the format of the written text are signs making the connection to the hacktivist collective/hacking community. As stated above, the song that Anonymous used to cover the video, "Take control" by Vakttus, is a hip-hop song that embeds political messages.

It should be added that the hip-hop genre, more specifically the sub-genre of political hip-hop, emerged in the 1980s to give voice to less powerful social groups, allowing them to express the social injustice that they faced in their daily lives, such as inequality and social exclusion. Artists belonging to this political genre of music compose songs with political messages, encouraging their listeners to fight for social justice.

This specific song that Anonymous used to cover its video has a political message. The song's lyrics encourage listeners to rebel against the elites, the Illuminati, who 'control their lives', who create fear and 'panic' in society, who are responsible for the inequalities and the social exclusion of less powerful social groups. According to the song, the only way to change this situation is for people to rewrite history by fighting against the powerful. Comparing the first and second attacks, we notice that in the first attack, it is the live figure/identity of Anonymous that conveys the political message of the attack by explaining the rationale, while in the second attack, the message is mediated by a hip-hop song that, because of its melody and lyrics, grabs the attention of the viewers/listeners. Also, in the second attack, contrary to the first one, there is a direct reference to the anti-Illuminati position of Anonymous [3].

As mentioned above, however, the visual representation of the second attack is accompanied by a text message analytically presenting the reasons for this new attack [64] in green lettering and in a font that recalls a programming language. The entire message is presented in the Greek language. Semiologically the style of the message, the green lettering against a black background, as well as the style of the font are all elements closely connected with hacking.

After the release of the movie The Matrix, which treats hacking and the life of a hacker, the use of this combination of lettering and background colors to signify hacking became a pop culture trope. Moreover, since all such actions take place in cyberspace, and hacking is an action intended to break codes, hackers do not care how the computer interface looks. The simplicity of the lettering/background presentation harkens back to the advent of computers, when computer monitors did not produce the full range of colors. In other words, the use of these two colors embeds information evoking the history of computer science, they are elements revealing the 'simplicity' and 'scientific valence' of hacking.

While representatives of the Anonymous collective were not performing as real persons in this video message, through the use of this song, which expresses political activism, and the use of the green lettering against a black background, which symbolizes hacking, they indirectly express their hacktivist identity.

Interpretive textual analysis: In the second attack on the Ministry of Justice, the after-attack message of Anonymous 'warned' the Greek government that if it passed legislation imposing strict taxation measures on Greek citizens, Anonymous would 
attack the digital infrastructure of the tax offices to protect the taxpayers by deleting their debts. In its rhetoric, Anonymous did not limit its action to threatening the Greek state and tax services, but also encouraged Greek citizens not to despair because Anonymous would be on their side. In this sense, Anonymous attempted to give a 'psychological lift' to Greek citizens, to help them cope with the hardships of the present situation. At any rate, Anonymous aimed to help the economically weak, seeking social justice.

The discourse in this video is also connected with the recurrent 'war' or revolutionary rhetoric of Anonymous. This 'war' rhetoric was not limited to an attempt to motivate Greek citizens to protest against their government, but shifted discussion from the street (i.e., citizen protests) and the real world, to the virtual world of cyberspace. According to Anonymous' rhetoric, while the state has the power to control and attack demonstrators and protestors, the Anonymous hacktivists have similar, or even more, power in cyberspace. In other words, cyberspace is where Anonymous has abilities and skills that enable it to defeat the state. In their worldview, the hackers and hacktivists in cyberspace who constitute the Anonymous collective are the principal and powerful actors, and that is why governments should be careful in their actions.

\subsubsection{Anonymous Versus the Ministry of Finance, October 2012 (Text)}

In October 2012, Anonymous attacked the Ministry of Finance [14] by leaking a number of its documents. This attack was accompanied by a message on social media and via the printed and digital news media. In a Facebook account that has long been named 'Anonymous - \#OpGreece', a text in the Greek language was published, which stated, among other things:

Your government will fail. Greek citizens, it's time to rebel. Do as much as you can. You have to resist. We are always at your side. We have full access to the Greek Ministry of Finance. The IBM servers do not seem so safe now, right?

We have new weapons in our arsenal. An excellent unmodified weakness for SAP systems is in our hands and, yes, we will use it to bring hell!

We have obtained secret government data, codes, etc. Citizens of Greece are paying banks and international firms for managing high-risk funds. It's your own life. Rebel before it's too late.

Austerity measures must go away. I have nothing to say.

Interpretive textual analysis: Anonymous exhibits its power and weapons by obtaining access to the Greek Ministry of Finance, which has one of the more advanced electronic systems in the Greek state. Using confident and strong emotive language, Anonymous keeps threatening that it will 'bring hell', calling for a sort of 'rebellion' by the Greek citizens against the austerity measures 'before it's too late'.

As we can see in the message accompanying this attack, Anonymous' rhetoric incorporates technical jargon in order to show its power. Anonymous talks about 
the vulnerability of digital infrastructure and how its skills can defeat the governmental websites. Aside from the war rhetoric ('We have new weapons in our arsenal') loaded with references from the technical world, we also find a call for a street rebellion addressed to the Greek people, urging them to protest to stop the ongoing unpopular policies. The message is purely political and brings to mind revolutions such as the French (1789) and Greek revolutions (1821), when people had to take the law into their own hands to change the status quo.

\subsubsection{Anonymous Versus the Greek Governmental Auction Website: September 2017 (Text)}

Anonymous uploaded a video [59] to its Greek Facebook page ('Anonymous Greece') explaining the purpose of the attack. This video is no longer available; however, what was still available at the time of the study was a written statement from Anonymous, reposted on news media websites, explaining the purpose of the attack. The message was in the Greek language and drew attention to the following matters:

Dear Greek Government,

In a country where access to health care has been a luxury for the poor, the misbehaving EOPYY [i.e., the National Agency for Health Services] refuses to cover the costs so Nefeli can go abroad to be treated for her serious illness. The time of electronic auctions is approaching, all the foreign ravens have taken their seats and are waiting to seize the fortunes of poor Greek citizens! Predatory, do you think that we'll let you do it? If you think so, you will be very disappointed, you will soon get the answer from Anonymous Greece and see the power of the Greeks! NO TO ELECTRONIC SEIZURES

Government masons or not, we will meet soon.

P.S. You calculated without considering the hotelier. Soon we will give you the 'keys to hand'.

In this message, Anonymous criticizes the cruel position of the Greek government, which did not cover the expenses of a ten-year-old girl diagnosed with cancer so she could continue the necessary chemotherapy abroad. The 'poor', according to Anonymous, are left to die or lose their precious belongings (i.e., homes). Anonymous indicates that it will block the plans of the 'Government masons' who constitute part of the Illuminati hierarchy. Anonymous' response was to target the destruction of the Greek website for the electronic auctions. If Anonymous fulfills this threat, we could argue that the group greatly resembles the figure of Robin Hood, who cared for the poor in a meaningful way.

Interpretive textual analysis: Anonymous wanted to emphasize that Greek society is discriminating against citizens from certain social categories, setting poor against rich. From this perspective, the poor and especially an innocent child seem to lack access to basic public goods, such as equal access to health, and are left literally to 
Table 2 Key characteristics of Anonymous in the Greek case

Characteristics of Anonymous

Anonymous as omnipotent agents in cyberspace

Anonymous fighting against a corrupt system

Anonymous as an ally/defender of the weakest citizens, particularly the poor

Anonymous as protectors of democracy and justice (causes with a strong political content)

Anonymous as mobilizers of street rebellion

die. Similarly, the poor segment of Greek population is about to lose its property due to the accumulation of private debts.

On the other side, the foreign and rich investors (metaphorically, 'foreign ravens') are waiting to seize the fortunes of poor Greek citizens via the government's electronic auctions. According to Van Leewen [63, p. 30], metaphor is a multimodal concept that can also apply to semiotic modes other than language, as in the case of political cartoons that often depict politicians as animals, or more precisely, as halfanimal, half-human.

The message of Anonymous finishes with another strong image, saying that 'You calculated without considering the hotelier. Soon we will give you the "keys to hand"'. This Greek adage signifies that they, i.e., the foreign creditors, forgot to consider the people concerned, i.e., the Greek people, and therefore incorrectly assessed the situation. In other words, Anonymous will stop soon this injustice towards poor Greek citizens by any means.

\subsection{Power Relations Resulting from the Cyber-Performances}

In the Greek case, Anonymous frequently refers to unfair reality (e.g., economic crisis, the resulting social despair, and the suppression of the weak), identifying an 'offender' as described earlier or an 'injustice' that the established system has failed to address (see, e.g., the reference to the sick child whose expenses the Greek Agency for Health Services did not cover). From this perspective, we learn more about the identity of the persons/institutions to be punished (i.e., perpetrators, such as the Greek state, foreign creditors, Illuminati, and Greek politicians). Remarkably, any sort of legal reasoning is completely absent.

Anonymous seeks to generate an opposing pole of power subject to the people's sovereignty, instead of to the state's monopoly on force. That is why at every opportunity, Anonymous uses in its videos the slogan from the movie $V$ for Vendetta, 'People shouldn't be afraid of their government. Governments should be afraid of their people', or 'Justice is coming'.

After critically examining the videos and texts of Anonymous, we will now look into the basic characteristics of the group's actions in the Greek context (see Table 2). Considering these characteristics will permit us to decide whether or not Anonymous is a new Robin Hood. 
Anonymous takes a one-sided approach, strongly defending the weakest parties in the causes it takes up, ignoring the potential arguments of the other side. In doing so, the group disseminates a plethora of accusations on the Internet, using strong emotive language, metaphors, and abstract terms, such as 'justice' and 'democracy'. Those two terms, 'justice' and 'democracy', have strong political connotations that can be interpreted differently from one individual to another, i.e., they are polysemous. At any rate, this polysemy advances the purposes of Anonymous, helping it gain the support of more people, since individuals tend to 'translate' its messages differently based on their own experiences and background.

In other countries and in Greece, the attacks of Anonymous are considered illegal by the authorities, since the group steals critical data from government websites or temporarily halts their normal function. The actions of Anonymous in the Greek case were intended to underline its superiority in cyber-space skills, to highlight the incapacity of Greek state authorities, and to start a 'war' on the Internet, if anyone provokes them. However, all of Anonymous' cyber-threats in the Greek context stayed unrealized. For example, Anonymous did not shut down the governmental system for online auctions, and did not erase electronic records of the debts of Greeks to the tax agencies. This shows that Anonymous is not as strong in the 'arena of real life' as it is on the Internet.

It is also worth viewing the cyber-performances of Anonymous in light of Goffman's [21, pp. 14-15] eight principles for analyzing face-to-face conversations. We have had to adapt these principles to the medium of the Internet, which creates new conditions for this sort of interaction.

In particular, we noticed from our examination of the texts and videos of Anonymous that the group uses one-way communication, merely transmitting recorded messages to the public. Despite this one-way interaction, Anonymous can still get feedback (e.g., comments and emoticons) from the viewers of its videos on the Internet, particularly via commercial platforms such as YouTube. However, the most problematic aspect of this particular type of communication between Anonymous' cyber-performers and their viewers remains the identification-authentication signs that are too vague, since anyone can effortlessly produce a video on YouTube using the rituals and signs of Anonymous (as also noted by Fish [16]), while the direct contact signals are completely lacking due to the wearing of masks. The transmitted videos are recorded and the viewers cannot have a channeled connection, as occurs during face-to-face interaction.

Furthermore, turnover signals do exist to some extent, for instance, the slogan 'We don't forgive, we don't forget, expect us', which usually signals to viewers the approaching end of a recorded message transmission. Preemption signals are also unavailable because there is no real conversation, which takes place in real time and space. The viewer of the video can only rerun the video and listen again to the recorded message of Anonymous, which contains many messages in just a few minutes of transmission. The framing capabilities in combination with the use of very vivid metaphors and emotive words characterize every video of Anonymous, while the group usually describes a problem that has to be fixed by the members of the group, since the group possesses a sort of cyber-authority on this matter. Ironically, in the case of Anonymous, there are no concrete norms obliging them to reply 
honestly, but it can say and do whatever it likes. Also, there are participant constraints, with the most important one being the lack of eye-to-eye signals and physical proximity. The viewers cannot be part of this 'virtual discussion' since they are simply the receivers of the message.

It is known from the literature that face-to-face meetings are a rich source of information, allowing individuals to learn a great deal about the identity of their interlocutors as regards their race, class identity, age, physical ability, attractiveness, and social skills [34, p. 136]. This information is not easily attainable in cyberspace [34, p. 136]. In the case of Anonymous, we believe that the lack of physical intimacy benefits the group and makes Anonymous more powerful when conducting its cyber-performances, since the viewer has a serious deficit of information about the real identity of the group. The viewer tries to compensate for this deficit with the images, language, signs, virtual actions that Anonymous uses in spreading its ideological message. The chances for misconception as regards the online identity of Anonymous are kept wide open. This means that the identities of Anonymous are as numerous as the minds of its viewers and supporters. In this spirit, the group of Anonymous preserves its online myth, along with its precious anonymity.

\section{Conclusion: Anonymous does not Implement the Motto 'steal from the rich to give to the poor'}

Could someone then claim that Anonymous is a contemporary expression of the Robin Hood impulse? The answer does not entail a simple 'yes' or 'no'. In view of our material, we realized that Anonymous recalls the image of Robin Hood, but since it operates in a completely different era, it is a more complicated actor to explicate and understand.

Based on the characteristics of Anonymous in the Greek case, we see the group as cyber-performers who 'command', 'request', and 'intimidate' with their ritual performances and employ various social semiotics in achieving its purposes, such as the mask of Guy Fawkes, which simultaneously symbolizes anonymity and rebellion against authority. Anonymous tends to exaggerate the group's power on the Internet by claiming that it could start a 'cyber-war' on the Internet.

Even given these characteristics, we argue that it is reasonable to establish some kind of link between Anonymous and Robin Hood, since Anonymous often seems to care greatly about the poor and about issues related to social justice and fairness that the official legal/political system cannot address effectively. These issues will always be front and center in human societies because they carry the 'seeds of durability', as does the ethical code of 'taking from the rich to give to the poor', which in modern terms signifies the reduction of social inequality. However, the biggest and most striking difference between the Anonymous cyber-performers and the medieval hero is that the former operate at the level of cyber-threats and return nothing tangible to those in great need, as happened in the Robin Hood myths.

Put more bluntly, Anonymous practically abstains from the motto 'steal from the rich to give to the poor', which is firmly associated with the name of the famous outlaw hero. In the Greek example, Anonymous failed to stop the confiscation of 
Greek citizens' property by the state, which continues to this very day without serious obstacles; in addition, to our knowledge there has been no registered attack on any tax office system to erase the debts of Greek citizens. Having this in mind, we claim that Anonymous is often restricted to disseminating empty politically motivated rhetoric against the government rather than taking real actions that could ultimately positively change the lives of 'ordinary' people, as Robin Hood did, at least as of the completion of this study.

To conclude, if Anonymous manages to move from the sphere of cyber-threats to more tangible implementation of Robin's Hood motto, we could definitely speak of an upgraded, digital version of the beloved hero. Only then would Anonymous be able to embody a new wave of redistributive justice with life-changing consequences for the underprivileged. Until this moment comes, we are keeping a close eye on the group's online identity, behavior, and actions.

Acknowledgements Both authors of this article would like to express their gratitude to the organizers and the participants of the 19th International Roundtable for the Semiotics of Law (IRSL 2018) which was hosted by the University of Örebro, Sweden, 23-25 May, 2018.

Open Access This article is distributed under the terms of the Creative Commons Attribution 4.0 International License (http://creativecommons.org/licenses/by/4.0/), which permits unrestricted use, distribution, and reproduction in any medium, provided you give appropriate credit to the original author(s) and the source, provide a link to the Creative Commons license, and indicate if changes were made.

\section{References}

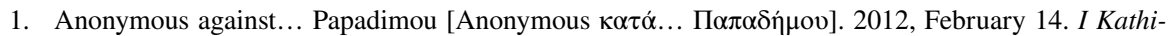
merini. http://www.kathimerini.gr/450478/article/epikairothta/politikh/anonymous-kata-papad hmoy. Accessed 11 Oct 2018.

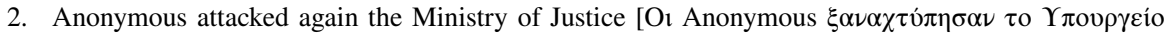

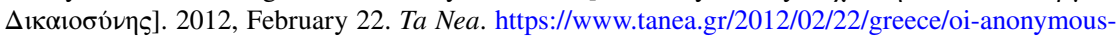
ksanaxtypisan-to-ypoyrgeio-dikaiosynis/. Accessed 11 Oct 2018.

3. ArchOikos. 2012. Anonymous: Hacked the Greek Ministry of Justice to send a message to Greek people. YouTube video, 02:10. Posted [February 3]. https://www.youtube.com/watch $? \mathrm{gl}=\mathrm{SN} \& \mathrm{hl}=\mathrm{fr} \& \mathrm{v}=\mathrm{CiNCsmGg0m0}$. Accessed 11 Oct 2018.

4. Auty, Caroline. 2004. Political hacktivism: Tool of the underdog or scourge of cyberspace? Aslib Proceedings: New Information Perspectives 56 (4): 212-221.

5. Bazelon, Emily. 2014. The online avengers. The New York Times Magazine 1-14. https://www. nytimes.com/2014/01/19/magazine/the-online-avengers.html. Accessed 10 Oct 2018.

6. Carter, Adam. 2012. From Anonymous to shuttered websites, the evolution of online protest. http:// www.cbc.ca/news/canada/story/2012/03/15/f-online-protest.html. Accessed 12 Oct 2018.

7. Chandler, Amanda. 1996. The changing definition and image of hackers in popular discourse. International Journal of the Sociology of Law 24: 229-251.

8. Coleman, Gabriella. 2013. Anonymous in context: The politics and power behind the mask. Internet Governance Paper 3: 1-22.

9. Coleman, Gabriella. 2014. Hacker, hoaxer, whistleblower, spy: The many faces of Anonymous. London and New York: Verso.

10. dearfoxnews. 2007. Anonymous: You have got our attention. YouTube video, 02:32. Posted [July 29]. https://www.youtube.com/watch?v=RFjU8bZR19A. Accessed 11 Oct 2018.

11. Derrick, Lisa. 2017. Anonymous shuts down Tunisian govt websites after violence and web censorship. Huffingtonpost. https://www.huffingtonpost.com/lisa-derrick/anonymous-shuts-downtuni_b_804342.html?guccounter=1. Accessed 10 Oct 2018. 
12. Deseriis, Marco. 2012. Improper names: Collective pseudonyms and multiple-use names as minor processes of subjectivation. Subjectivity 5 (1): 140-160.

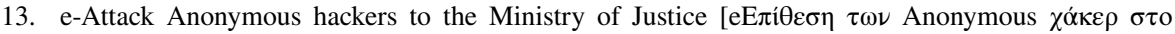

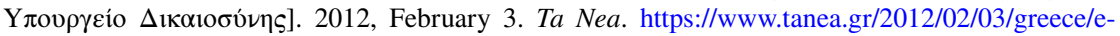
epithesi-twn-anonymous-xaker-sto-ypoyrgeio-dikaiosynis/. Accessed 11 Oct 2018.

14. Exposure of hundreds of documents from the Greek Ministry of Finance [ $\Delta 1 \alpha \rho \rho \circ \eta \dot{~ \varepsilon \kappa \alpha \tau o \nu \tau \alpha ́ \delta \omega \nu ~}$

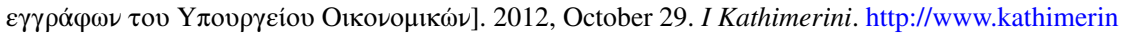
i.gr/17938/article/epikairothta/ellada/diarroh-ekatontadwn-eggrafwn-toy-ypoyrgeioy-oikonomikwn. Accessed 11 Oct 2018.

15. Featherstone, Kevin. 2005. Introduction: 'Modernisation' and the structural constraints of Greek politics'. West European Politics 25 (2): 223-241.

16. Fish, Adam. 2015. Mirroring the videos of anonymous: Cloud activism, living networks, and political mimesis. The Fibreculture Journal Digital Media + Networks + Transdisciplinary Critique 26: 85-107.

17. Fuchs, Christian. 2013. The Anonymous movement in the context of liberalism and socialism. Interface: A Journal for and About Social Movements 5 (2): 345-376.

18. Georgiopoulos, Georgios. 2016, May 4. Anonymous attack Greek central bank, warns others. Reuteurs, Technology News. https://uk.reuters.com/article/us-greece-cenbank-cyber/anonymous-attac k-greek-central-bank-warns-others-idUKKCNOXV0RR. Accessed 11 Oct 2018.

19. Goffman, Erving. 1959. The presentation of self in everyday life. Garden City, New York: Doubleday.

20. Goffman, Erving. 1966/1963. Behavior in public places. Notes on the social organization of gatherings. New York: The Free Press.

21. Goffman, Erving. 1981. Forms of talk. Philadelphia: University of Pennsylvania Press.

22. Hai-Jew, Shalin. 2013. Action potentials: Extrapolating an ideology from the Anonymous hacker socio-political movement (A qualitative meta-analysis). In Digital democracy and the impact of technology on governance and politics: New globalized practices, ed. Christina Akrivopoulou and Nicolas Garipidis, 51-107. Hershey, PA: Information Science Reference.

23. Halliday, Michael. 1978. Language as social semiotic. London: Arnold.

24. Hamspon, Noah. 2012. Hacktivism: A new breed of protest in a networked world. Boston College International and Comparative Law Review 35 (2): 511-542.

25. Hardy, Cynthia, Thomas Lawrence, and David Grant. 2005. Discourse and collaboration: The role of conversations and collective identity. Academy of Management Review 30: 58-77.

26. Hodge, Robert, and Gunther Kress. 1988. Social semiotics. Cambridge: Polity.

27. Hobsbawm, Eric. 1972. Social bandits: Reply. Comparative Studies in Society and History 14 (4): 503-505.

28. Iedema, Rick. 2001. Analysing film and television: A social semiotic account of hospital. An unhealthy business. In Handbook of visual analysis, ed. Theo van Leeuwen and Carey Jewitt, 183204. London: Sage.

29. Jewitt, Carey, and Rumiko Oyama. 2001. Visual meaning: A social semiotic approach. In Handbook of visual analysis, ed. Theo van Leeuwen and Carey Jewitt, 134-156. London: Sage.

30. Jordan, Tim. 2002. Activism! Direct action, hacktivism and the future of society. London: Reaktion Books.

31. Jordan, Tim, and Paul Taylor. 2004. Hacktivism and cyberwars: Rebels with a cause?. London: Routledge.

32. Karagianopoulos, Vasileios. 2018. Living with hacktivism: From conflict to symbiosis. London: Palgrave Macmillan.

33. Kazmi, Ayesha. 2011. How Anonymous emerged to occupy Wall Street. The Guardian. September 27. https://www.theguardian.com/commentisfree/cifamerica/2011/sep/27/occupy-wall-street-anony mous. Accessed 10 Oct 2018.

34. Kendall, Lori. 1998. Meaning and identity in 'cyberspace': The performance of gender, class, and race online. Symbolic Interaction 21 (2): 129-154.

35. King, Brayden G., Teppo Felin, and David A. Whetten. 2010. Finding the organization in organizational theory: A meta-theory of the organization as a social actor. Organization Science 21: 290-305.

36. Knappenberger, Brian, John Dragonetti, Lincoln Else, Dan Krauss, Scott Sinkler, and Andy Robertson. 2012. We are legion: The story of the hacktivists. https:/www.youtube.com/watch?v=-zwDho Xpk90. Accessed 11 Oct 2018. 
37. Kress, Gunther, and Theo Van Leeuwen. 1996. Reading images: The grammar of visual design. London: Routledge.

38. Kress, Gunther, and Theo Van Leeuwen. 2001. Multimodal discourse: The modes and media of contemporary communication. London: Arnold.

39. Kress, Gunther, and Theo Van Leeuwen. 2002. Colour as a semiotic mode: Notes for a grammar of colour. Visual Communication 1 (3): 343-368.

40. Lemert, Charles, and Ann Branaman (eds.). 1997. The Goffman reader. Malden: Blackwell Publishing.

41. Macphail, Cameron, and Keely Lockhart. 2017, November 6. Gunpowder, treason and plot: The story behind Bonfire Night and Guy Fawkes. The Telegraph. https://www.telegraph.co.uk/news/0/ gunpowder-treason-plot-story-behind-bonfire-night-guy-fawkes/. Accessed 11 Oct 2018.

42. Manion, Mark, and Abby Goodrum. 2000. Terrorism or civil disobedience: Toward a hacktivist ethic. Computers \& Society 30 (2): 14-19.

43. Milan, Stefania. 2016. Hackers, hacktivists, and the fight for human rights in cybersecurity. European Cybersecurity Journal 2 (2): 18-21.

44. MrAnonymousGR. 2012. Anonymous second message to Greece (Greek subtitles). YouTube video, 09:58. Posted [February 9]. https://www.youtube.com/watch?v=6L16Nh9vd60. Accessed 11 Oct 2018.

45. Norton, Quinn. 2012. How Anonymous picks targets, launches attacks, and takes powerful Organizations Down. Wired.com. http://www.wired.com/threatlevel/2012/07/ff_anonymous/all/. Accessed 10 Oct 2018 .

46. Nöth, Winfried. 2012. Visual semiotics: Key features and an application to picture ads. In Handbook of visual research methods, ed. Eric Margolis and Luc Pauwels. London: Sage Publications. https://doi.org/10.4135/9781446268278.n16.

47. Olson, Parmy. 2013. We are Anonymous: Inside the hacker world of LulzSec, Anonymous, and the global cyber insurgency. London: William Heinemann.

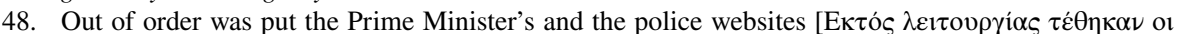

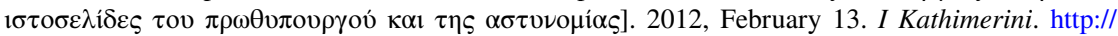
www.kathimerini.gr/77131/article/texnologia/diadiktyo/ektos-leitoyrgias-te8hkan-oi-istoselide s-toy-prw8ypoyrgoy-kai-ths-astynomias. Accessed 11 Oct 2018.

49. Peirce, C.S. (1931-1958) Collected papers. Cambridge, MA: Harvard University Press.

50. Pollard, A.J. 2005. Imagining Robin Hood: The late Medieval stories in historical context. London: Routledge.

51. von Platz, Jeppe. 2016. Robin Hood justice: Why Robin Hood took from the rich and gave to the poor (and we should too). Public Affairs Quarterly, 3 (2): 149-170.

52. Raymond, Mark, and Gordon Smith (eds.). 2014. Organized chaos: Reimagining the internet. Waterloo: McGill-Queen's University Press.

53. Robinson, Laura. 2007. The cyberself: The self-ing project goes online, symbolic interaction in the digital age. New Media \& Society 9 (1): 93-110.

54. Sauter, Molly. 2013. LOIC will tear us apart": The impact of tool design and media portrayals in the success of activist DDOS attacks. American Behavioral Scientist 57 (7): 983-1007.

55. Souliotis, Giannis. 2012, February 4. A victim of an online attack the Ministry's of Justice web-

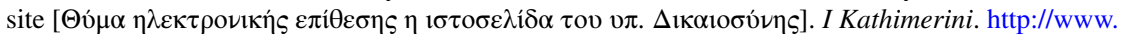
kathimerini.gr/449524/article/epikairothta/politikh/8yma-hlektronikhs-epi8eshs-h-istoselida-toy-ypdikaiosynhs. Accessed 11 Oct 2018.

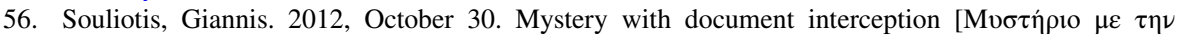

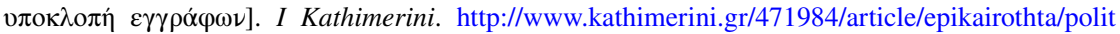
ikh/mysthrio-me-thn-ypokloph-eggrafwn. Accessed 11 Oct 2018.

57. Taylor, Paul. 2005. From hackers to hacktivists: Speed bumps on the global superhighway? New Media \& Society 7 (5): 625-646.

58. Taylor, Paul, and Jan Harris. 2006. Hacktivism. In Handbook of information security: Information warfare, social, legal, and international issues and security foundations, vol. 2, ed. Hossein Bidgoli, 172-182. New Jersey, NJ: Wiley.

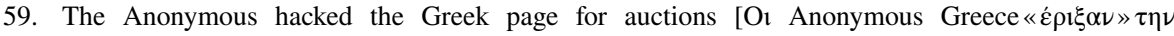

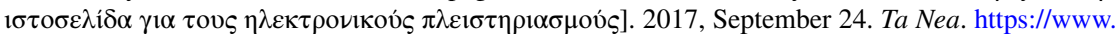
cnn.gr/news/ellada/story/98813/oi-anonymous-greece-erixan-tin-istoselida-gia-toys-ilektronikoyspleistiriasmoys. Accessed 11 Oct 2018. 
60. Thomas, Jim. 2005. The moral ambiguity of social control in cyberspace: A retroassessment of the 'golden age' of hacking. New Media \& Society 7 (5): 599-624.

61. Valentova, Eva. 2015. The chaotic freedom fighter: Anonymous as the trickster of cyberculture. New Directions in Folklore 13 (1/2): 44-70.

62. Van Leeuwen, Theo. 2001. Semiotics and iconography. In Handbook of visual analysis, ed. Theo van Leeuwen and C. Jewitt, 92-118. London: Sage.

63. Van Leeuwen, Theo. 2005. Introducing social semiotics. London: Routledge.

64. XTpower. 2012. \#OpGreece: Anonymous 2nd attack on Greek ministry of justice. 03:34. Posted [February 22]. https://www.youtube.com/watch?v=B93fBDfX8QY. Accessed 11 Oct 2018.

Publisher's Note Springer Nature remains neutral with regard to jurisdictional claims in published maps and institutional affiliations. 